\title{
Japanese Stock Markets and the US Stock Price Index Ratios
}

\author{
Chikashi Tsuji \\ Faculty of Economics, Chuo University, Tokyo, Japan \\ Correspondence: Chikashi Tsuji, Professor, Faculty of Economics, Chuo University 742-1 Higashinakano Hachioji-shi, \\ Tokyo 192-0393, Japan
}

Received: July 7, 2014

Accepted: July 17, 2014

Available online: August 12, 2014

doi:10.11114/aef.v1i2.485

URL: http://dx.doi.org/10.11114/aef.v1i2.485

\begin{abstract}
This paper investigates which US stock price index is strongly influenced by the Japanese stock markets. Our empirical tests as to the time-varying correlations derived from a multivariate generalized autoregressive conditional heteroskedasticity (MGARCH) model reveal the following evidence. First, (1) we clarify that all US stock returns of the Dow Jones, S\&P 500, and NASDAQ Composite indices are statistically significantly positively influenced by the returns of TOPIX and the Nikkei 225. Moreover, we also find that (2) the changes of the NASDAQ-S\&P 500 (NS) ratio are statistically significantly positively influenced by the returns of TOPIX and the Nikkei 225 while the changes of the Dow Jones-S\&P 500 (DS) ratio and the Dow Jones-NASDAQ (DN) ratio are statistically significantly negatively influenced by the returns of TOPIX and the Nikkei 225. These relations between the returns of TOPIX and the Nikkei 225 and the US stock price index ratios are clearly shown in all three sample periods employed in this paper. Hence our results suggest that, in our analyzing periods, (3) the NASDAQ index is most strongly positively connected with the Japanese stock markets.
\end{abstract}

Keywords: Dow Jones, NASDAQ, S\&P 500, Nikkei 225, TOPIX, DN ratio, DS ratio, NS ratio

JEL Classification Codes: G12, G15

\section{Introduction}

The Dow Jones, S\&P 500, and NASDAQ Composite Index are well-known stock price indices in the US and many investors pay attention to their dynamics. However, the differences of their characteristics of dynamics due to their structural differentials seem not to be analyzed, in particular, by academicians. Surveying the academic researches related with the stock price indices in the US, there are indeed many empirical studies. For example, Durham (2007) applied the stochastic volatility mixture model to the S\&P 500 index returns and suggested that the stochastic volatility mixture model was strongly preferred. Becker et al. (2009) investigated the jump component of the S\&P 500 volatility and S\&P 500 volatility index (VIX). Anderson et al. (2010) examined the presence of periodically and partially collapsing speculative bubbles in the sector indices of the S\&P 500. Mollick and Assefa (2013) examined the US stock returns such as the S\&P 500 and Dow Jones based on the information included in several financial and economic variables. Narayan and Thuraisamy (2013) explored the common trends and cycles in the S\&P 500, Dow Jones and NASDAQ. As above, even in the US, there is little academic research on the stock index ratios such as Dow Jones-S\&P 500 (DS) ratio, Dow Jones-NASDAQ (DN) ratio, or NASDAQ-S\&P 500 (NS) ratio as our present study.

Based on our motivation and the situation of the existing literature documented above, this paper aims to clarify which US stock index is most strongly influenced by the Japanese stock markets by analyzing three US stock price index ratios. We note that we investigate the same day closing price data as to the US and the Japanese stock price indices in this study; because of the time difference between the US and Japan, by analyzing the same day data, we can examine the influence of the Japanese stock markets on the US equity markets since the US stock prices are observed after the closing prices of the Japanese stock price indices are given. As a result, our empirical examinations with regard to the time-varying correlations obtained from a multivariate generalized autoregressive conditional heteroskedasticity (MGARCH) model (the BEKK-MGARCH model (Engle and Kroner; 1995)) derive the following evidence and contributions. First, (1) we clarify that all US stock returns of the Dow Jones, S\&P 500, and NASDAQ Composite indices are statistically significantly positively influenced by the returns of TOPIX and the Nikkei 225. Moreover, we also find that (2) very interestingly, the changes of the NS ratio are statistically significantly positively influenced by the returns of TOPIX and the Nikkei 225 while the changes of the DS ratio and DN ratio are statistically significantly 
negatively influenced by the returns of TOPIX and the Nikkei 225. These relations between the returns of TOPIX and the Nikkei 225 and the changes of the US stock price index ratios are clearly shown in all three sample periods employed in this paper. Therefore, our evidence demonstrates that (3) the NASDAQ index is most strongly connected with the Japanese stock markets. The rest of the paper is organized as follows. Section 2 supplies the literature review, Section 3 explains our data and methodology, Section 4 describes our empirical results, and Section 5 concludes the paper.

\section{Literature Review}

This section reviews the literature that studied the US stock price indices such as the Dow Jones, S\&P 500, and NASDAQ Composite index. First, Brock et al. (1992) found that by applying technical rules to the Dow Jones, trading profits could be earned. Whilst Day and Wang (2002) reexamined this finding and they concluded that estimates of trading profits derived from more accurately adjusted closing price levels of the Dow Jones were not significantly different from simple buy and hold returns. Darrat et al. (2003) investigated the contemporaneous and lead-lag relations between trading volumes and return volatility in all stocks included in the Dow Jones. Chen and De Bondt (2004) studied all firms in the S\&P 500 index since 1976, and they suggested that the strategies of buying profitable stocks (winners) and selling unprofitable stocks (losers) performed well for periods up to one year and possibly longer.

Durham (2007) applied the stochastic volatility mixture model to the S\&P 500 index returns and concluded that the stochastic volatility mixture model was strongly preferred. Further, Becker et al. (2009) investigated the jump component of the S\&P 500 volatility and the S\&P 500 volatility index (VIX). Anderson et al. (2010) tested the existence of the speculative bubbles in the sector indices of the S\&P 500, and they found that well over half of the S\&P 500 index by market capitalization and seven of its ten sector component indices demonstrated some bubble-like behavior. Choudhry (2010) investigated the daily data of the Dow Jones index from January 1939 to December 1945 and found that the majority of the wartime events labelled important by historians did result in structural breaks in both price movement and stock return volatility.

Gospodinov and Jamali (2012) examined the effects of expected and surprise components in Federal funds target rate changes on realized and implied volatility of the S\&P 500, and they found that surprise changes in the target rate significantly increased volatility. Kaeck and Alexander (2012) applied Markov chain Monte Carlo methods to the time series data on the S\&P 500 index returns to estimate affine and non-affine stochastic volatility models where jumps were allowed; they concluded that the inclusion of jumps was less important than allowing for non-affine dynamics. Mollick and Assefa (2013) investigated the US stock price index returns such as the S\&P 500 and Dow Jones based on the information included in inflation expectations, VIX volatility, interest rates, gold prices, and the USD/Euro exchange rate. Narayan and Thuraisamy (2013) examined the common trends and common cycles in the S\&P 500, Dow Jones, and the NASDAQ. Further, the interesting study by Karolyi and Stulz (1996) examined the US and Japanese stock markets; however, their analyzing angle and method were different from our present study.

As above, there is little academic research on the stock index ratios such as DS ratio, DN ratio, or NS ratio in the US academic literature although analyzing the time-series of such ratios is interesting and useful to deepen our knowledge as to the US equity market dynamics.

\section{Data and Methodology}

This section documents our data and our methodology. All data used in this paper are obtained from the QUICK Corp. Our first variable DLTOPIX represents the first log difference of the daily closing price of TOPIX. The variable is computed as the percentage log return by multiplying 100 . We note that we use the percentage log return for all return variables used in this study. Similarly, DLNIKKEI denotes the percentage log return calculated from the daily closing price of the Nikkei 225; DLDOW is the percentage log return of the Dow Jones; DLSP means that of the S\&P 500; DLNASDAQ represents that of the NASDAQ.

Next, DLDS is the percentage log difference of the DS ratio, which is computed as the closing price of the Dow Jones divided by the closing price of the S\&P 500. Similarly, DLDN is the percentage log difference of the DN ratio, which is computed as the closing price of the Dow Jones divided by the closing price of the NASDAQ; DLNS denotes the percentage log difference of the NS ratio, which is computed as the closing price of the NASDAQ divided by the closing price of the S\&P 500. Our full sample period is from 1 September 1987 to 24 March 2014.

Figure 1 shows the daily dynamics of the several stock price index ratios in the United States: Panel A displays DS ratio; Panel B shows DN ratio; Panel C exhibits NS ratio. Due to the IT bubbles, around the year of 2000, DN ratio declined; on the other hand, NS ratio increased. This is because the NASDAQ index includes more information technology related shares than other two indices. 
Panel A. Dow Jones-S\&P 500 ratio

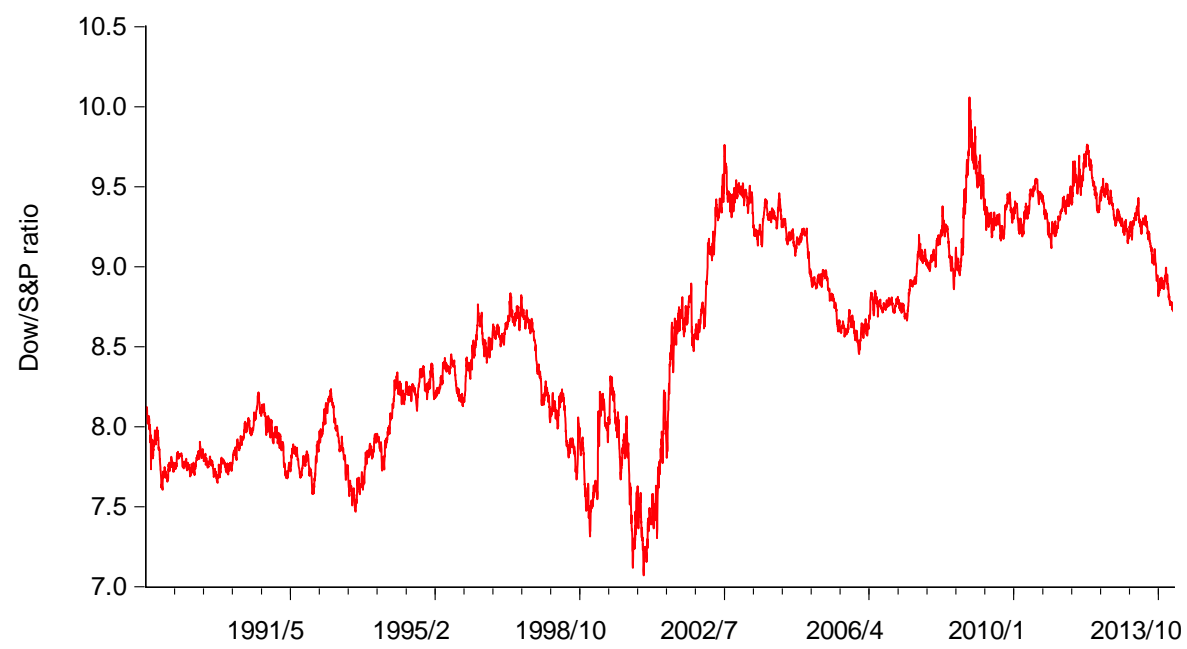

Panel B. Dow Jones-NASDAQ ratio

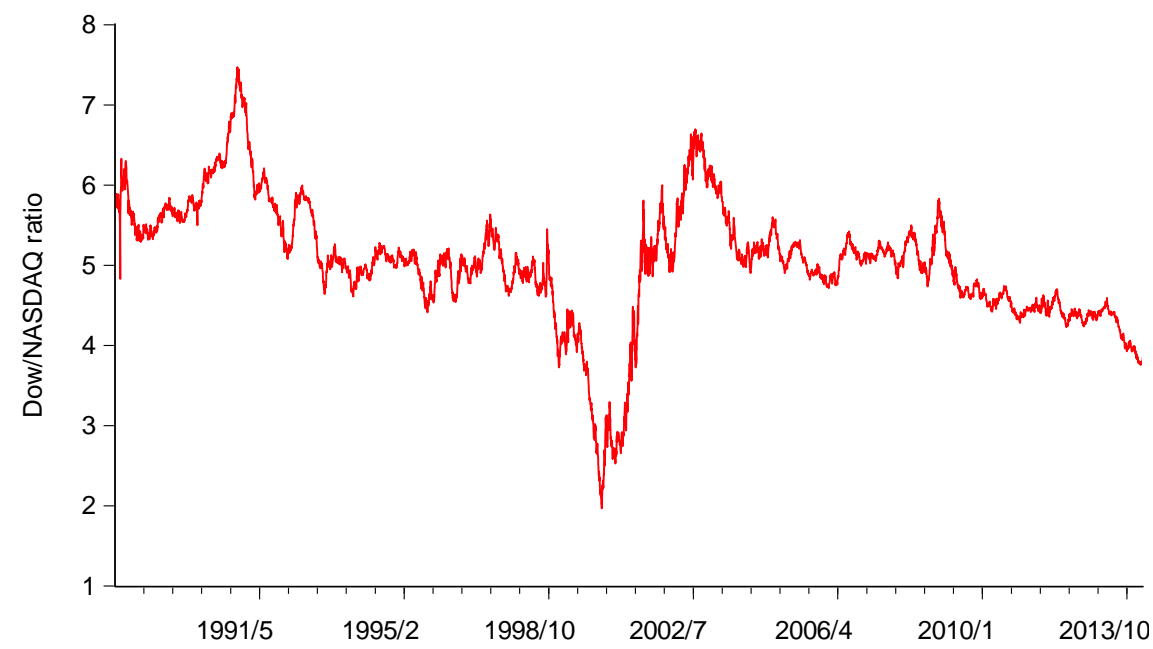

Panel C. NASDAQ-S\&P 500 ratio

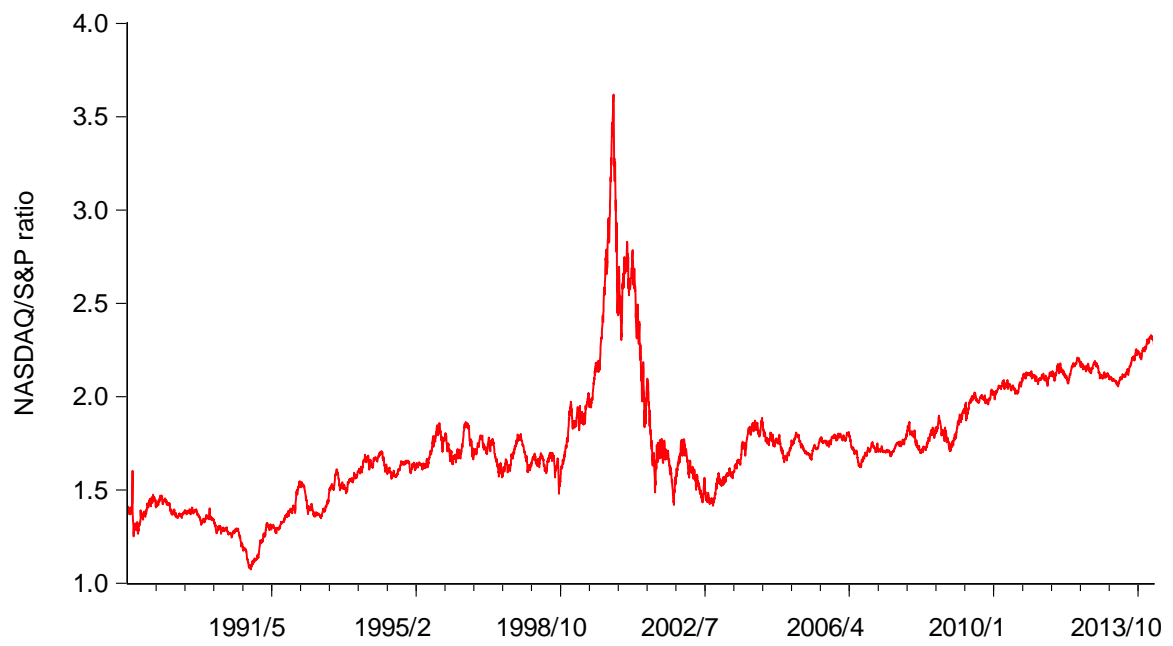

Figure 1. Daily dynamics of several stock price index ratios in the United States: Time-series evolution for the period from September 1987 to March 2014 
Panel A. DLTOPIX to DLDS

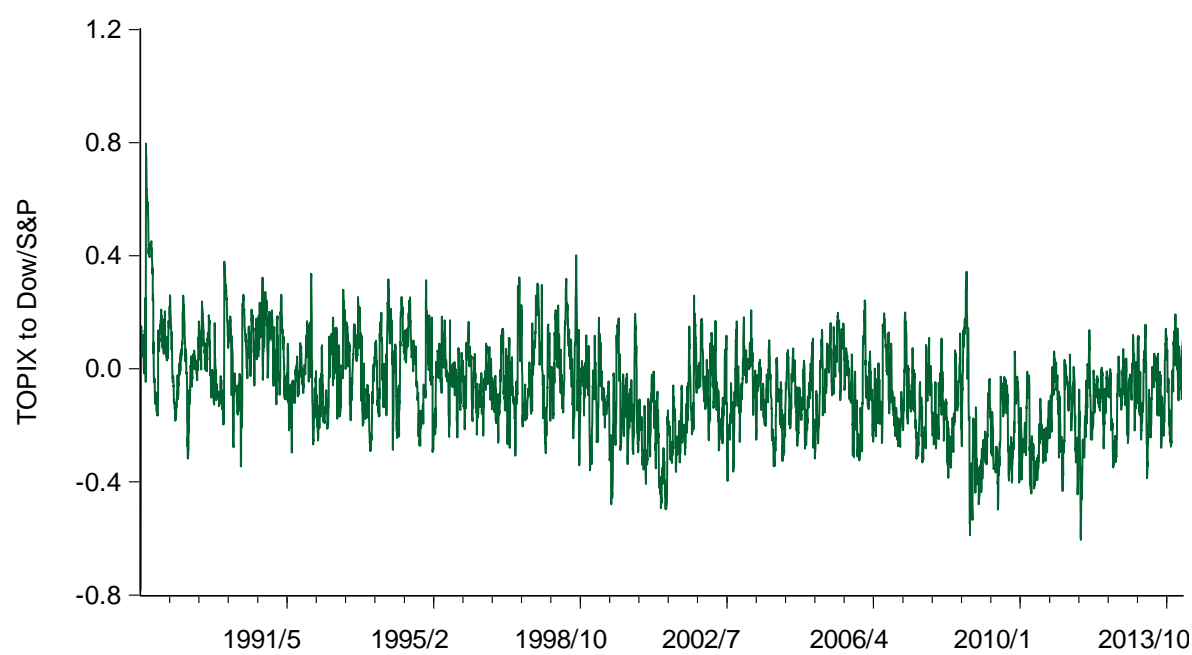

Panel B. DLTOPIX to DLDN

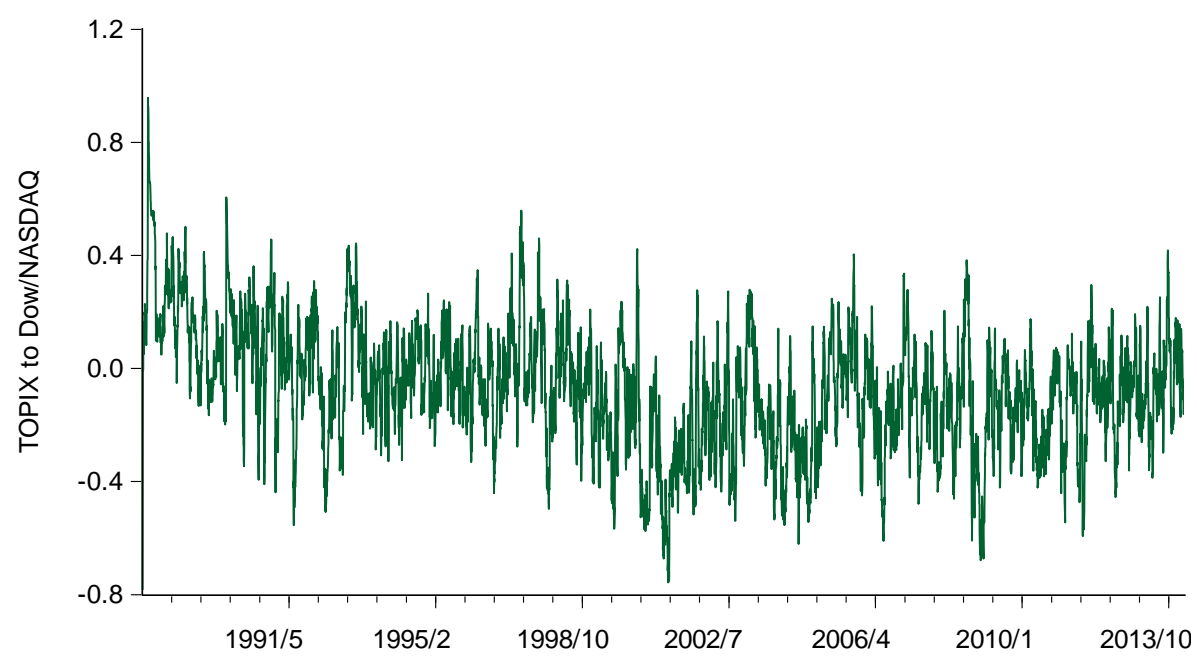

Panel C. DLTOPIX to DLNS

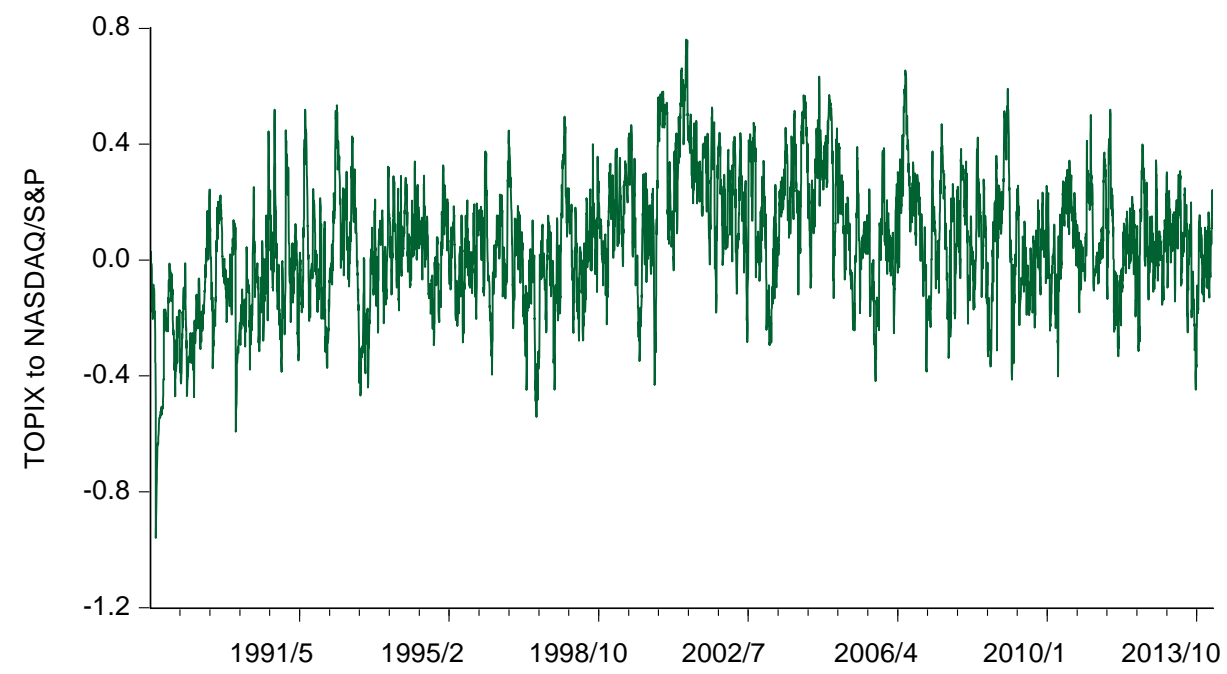

Figure 2. Daily dynamics of the correlation coefficients between the TOPIX changes and the changes of the US stock price index ratios: Time-series evolution for the period from September 1987 to March 2014 
Panel A. DLNIKKEI to DLDS

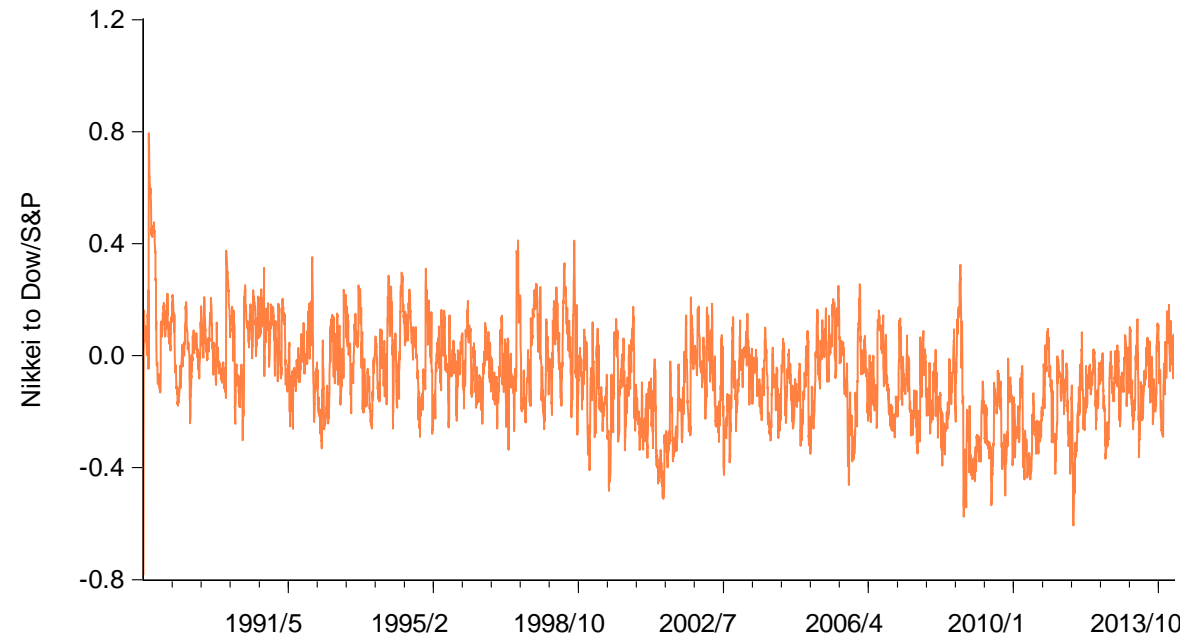

Panel B. DLNIKKEI to DLDN

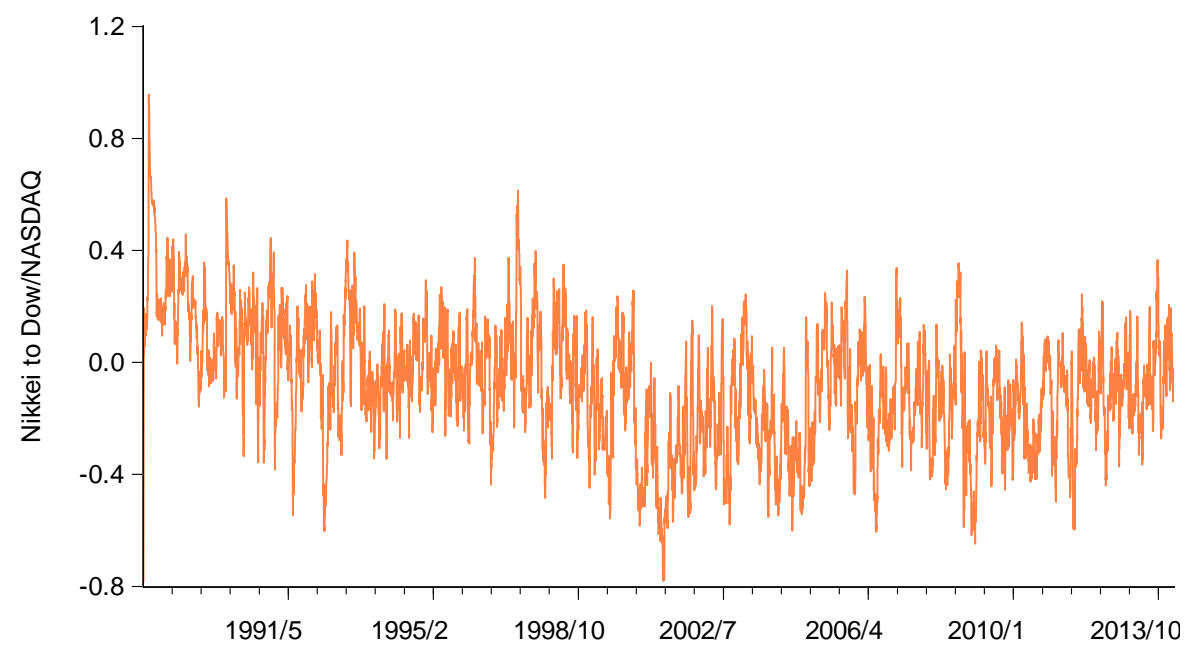

Panel C. DLNIKKEI to DLNS

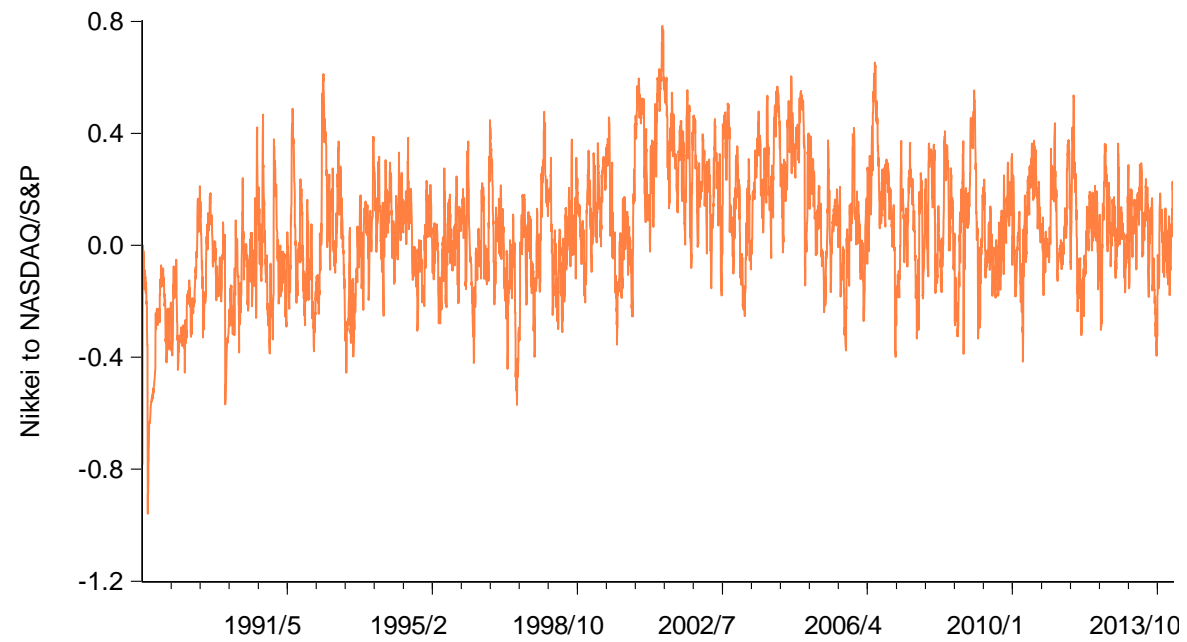

Figure 3. Daily dynamics of the correlation coefficients between the Nikkei 225 changes and the changes of the US stock price index ratios: Time-series evolution for the period from September 1987 to March 2014 
Table 1. Descriptive statistics of the variables for the full sample period and two sub-sample periods

Panel A. Results for the full sample period from September 1, 1987 to March 24, 2014

\begin{tabular}{|c|c|c|c|c|}
\hline & DLTOPIX & DLNIKKEI & DLDOW & DLSP \\
\hline Mean & -0.0097 & -0.0093 & 0.0289 & 0.0276 \\
\hline Standard deviation & 1.3746 & 1.5478 & 1.1915 & 1.2245 \\
\hline Skewness & -0.3690 & -0.3116 & -1.7719 & -1.2990 \\
\hline \multirow[t]{2}{*}{ Kurtosis } & 8.4463 & 7.3256 & 40.6511 & 26.7780 \\
\hline & DLNASDAQ & DLDS & DLDN & DLNS \\
\hline Mean & 0.0353 & 0.0013 & -0.0064 & 0.0077 \\
\hline Standard deviation & 1.5039 & 0.3177 & 0.9752 & 0.8010 \\
\hline Skewness & -0.3509 & 0.1068 & 0.5876 & -0.9232 \\
\hline Kurtosis & 6.0080 & 4.3846 & 22.7311 & 30.1642 \\
\hline
\end{tabular}

Panel B. Results for the before Lehman shock period from September 1, 1987 to September 12, 2008

\begin{tabular}{|c|c|c|c|c|}
\hline & DLTOPIX & DLNIKKEI & DLDOW & DLSP \\
\hline Mean & -0.0120 & -0.0151 & 0.0294 & 0.0270 \\
\hline Standard deviation & 1.2961 & 1.4639 & 1.1242 & 1.1148 \\
\hline Skewness & -0.3516 & -0.1776 & -2.5791 & -1.9016 \\
\hline \multirow[t]{2}{*}{ Kurtosis } & 8.0634 & 6.3721 & 58.7691 & 39.9203 \\
\hline & DLNASDAQ & DLDS & DLDN & DLNS \\
\hline Mean & 0.0320 & 0.0024 & -0.0027 & 0.0051 \\
\hline Standard deviation & 1.4708 & 0.3232 & 1.0547 & 0.8728 \\
\hline Skewness & -0.3116 & 0.0483 & 0.5638 & -0.8750 \\
\hline Kurtosis & 6.1222 & 4.4545 & 20.5947 & 26.4961 \\
\hline
\end{tabular}

Panel C. Results for the after Lehman shock period from September 16, 2008 to March 24, 2014

\begin{tabular}{|c|c|c|c|c|}
\hline & DLTOPIX & DLNIKKEI & DLDOW & DLSP \\
\hline Mean & -0.0009 & 0.0130 & 0.0272 & 0.0303 \\
\hline Standard deviation & 1.6428 & 1.8360 & 1.4216 & 1.5777 \\
\hline Skewness & -0.3904 & -0.5735 & -0.1484 & -0.3660 \\
\hline \multirow[t]{2}{*}{ Kurtosis } & 7.7600 & 7.7807 & 8.5371 & 8.2622 \\
\hline & DLNASDAQ & DLDS & DLDN & DLNS \\
\hline Mean & 0.0480 & -0.0031 & -0.0208 & 0.0177 \\
\hline Standard deviation & 1.6255 & 0.2959 & 0.5749 & 0.4234 \\
\hline Skewness & -0.4642 & 0.3910 & 0.3349 & -0.5832 \\
\hline Kurtosis & 5.5115 & 3.8265 & 1.5321 & 7.0111 \\
\hline
\end{tabular}

Notes: DLTOPIX denotes the first log difference of the daily closing price of TOPIX and the variable is computed as the percentage log return by multiplying 100 . We note that we use the percentage log return for all return variables. Similarly, DLNIKKEI denotes the percentage log return calculated from the daily closing price of the Nikkei 225; DLDOW means the percentage log return of the Dow Jones; DLSP denotes that of the S\&P 500; DLNASDAQ means that of the NASDAQ. Further, DLDS denotes the percentage log difference of the DS ratio, which is computed as the closing price of the Dow Jones divided by that of the S\&P 500. Similarly, DLDN means the percentage log difference of the DN ratio, which is computed as the closing price of the Dow Jones divided by that of the NASDAQ; DLNS denotes the percentage log difference of the NS ratio, which is computed as the closing price of the NASDAQ divided by that of the S\&P 500 . 
Further, Figure 2 displays the dynamics of the time-varying correlation coefficients between DLTOPIX (the first log difference of the daily closing price of TOPIX in percent) and the US stock price index ratio changes. More concretely, in Figure 2, Panel A shows the time-varying correlation coefficients between DLTOPIX and DLDS (the percentage log difference of the DS ratio); Panel B displays the time-varying correlation coefficients between DLTOPIX and DLDN (the percentage $\log$ difference of the DN ratio); Panel C shows the time-varying correlation coefficients between DLTOPIX and DLNS (the percentage log difference of the NS ratio). We understand that the time-series dynamics of correlation coefficients exhibited in Panels A and B are roughly below zero in average; while the time-series shown in Panel $\mathrm{C}$ move roughly above zero in average.

Moreover, Figure 3 displays the time-varying correlation coefficients between DLNIKKEI (the first log difference of the daily closing price of the Nikkei 225 in percent) and the US stock price index ratio changes. Specifically, in Figure 3, Panel A shows the time-varying correlation coefficients between DLNIKKEI and DLDS; Panel B displays the time-varying correlation coefficients between DLNIKKEI and DLDN; Panel C shows the time-varying correlation coefficients between DLNIKKEI and DLNS. We again understand that the time-series dynamics of correlation coefficients shown in Panels A and B are roughly below zero in average; while the time-series exhibited in Panel C move roughly above zero in average. As we documented, all time-varying correlation coefficients above are derived from the BEKK-MGARCH model.

Next, Table 1 displays the descriptive statistics for our five log stock price index returns and three log changes of the US stock price index ratios. This table shows some interesting data characteristics. Namely, as to the log returns of TOPIX, the Nikkei 225, and NASDAQ, similar kurtosis values are shown throughout our sample period; however, the log returns of the Dow Jones and S\&P 500 display extremely higher kurtosis values in the period before the Lehman shock in the US. In addition, regarding the US stock price index ratios, the log changes of DS ratio show similar kurtosis values throughout our sample period; however, the log changes of DN ratio and NS ratio show extremely higher kurtosis values in the period before the Lehman shock.

Furthermore, with respect to our testing methodology, we scrutinize the time-varying correlation coefficients between the log returns of TOPIX or the Nikkei 225 and the log changes of the US stock price index ratios by using the $t$-tests for their average values. By the tests, we aim to clarify which stock price index in the US is strongly influenced by the Japanese stock markets. Moreover, in our tests, we use the full sample period and two sub-sample periods before and after the Lehman shock.

\section{Empirical Results}

This section describes our empirical results. Our test results are shown in Tables 2 and 3. First, (1) Table 2 exhibits the $t$-test results for the time-varying correlation coefficients between the log returns of TOPIX and the log returns of the Dow Jones, S\&P 500, and NASDAQ. Table 2 also indicates the time-varying correlation coefficients between the log returns of TOPIX and the log changes of DS ratio, DN ratio, and NS ratio. Second, (2) Table 3 shows the $t$-test results for the time-varying correlation coefficients between the log returns of the Nikkei 225 and the log returns of the Dow Jones, S\&P 500, and NASDAQ. Table 3 also displays the time-varying correlation coefficients between the log returns of the Nikkei 225 and the log changes of DS ratio, DN ratio, and NS ratio.

In both Tables 2 and 3, the results for our full sample period and two-sub sample periods are displayed. More concretely, Panel As of Tables 2 and 3 show the test results for the full sample period; Panel Bs of Tables 2 and 3 indicate the test results for the sub-sample period before the Lehman shock in the US; Panel Cs of these tables demonstrate the test results for the sub-sample period after the Lehman shock. We again note that we investigate the same day return and ratio data as to the US and Japanese stock price indices; because of the time difference between the US and Japan, the US stock prices are observed as the closing prices of the Japanese stock price indices are given. Hence we can examine the influence of the Japanese stock markets on the US equity markets by analyzing their same day closing price data. By the tests, therefore, we can clarify which stock price index in the US is most strongly influenced by the Japanese stock market dynamics.

Explaining the test results in short, all the US stock returns of the Dow Jones, S\&P 500, and NASDAQ are statistically significantly positively influenced by the TOPIX and Nikkei 225 returns regardless of our sample periods. Further, very interestingly, the NS ratio changes are statistically significantly positively influenced by the TOPIX and Nikkei 225 returns while the changes of DS ratio and DN ratio are statistically significantly negatively influenced by the TOPIX and Nikkei 225 returns. These relations between the TOPIX and Nikkei 225 returns and the US stock price index ratios are consistently shown in all three sample periods employed in this paper. Therefore, it is the NASDAQ index that is most strongly positively connected with the Japanese stock markets, and this is very clear, robust, and informative evidence and contribution derived from our investigations. 
Table 2. Tests of the average values of the time-varying correlation coefficients between the changes of TOPIX and the US variable changes

Panel A. Results for the full sample period from September 1, 1987 to March 24, 2014

\begin{tabular}{llll}
\hline & DLTOPIX to DLDOW & DLTOPIX to DLSP & DLTOPIX to DLNASDAQ \\
\hline Correlation coefficient & $0.3889 * * *$ & $0.4064 * * *$ & $0.3654 * * *$ \\
$t$-value & 33.5611 & 35.3679 & 31.2118 \\
$p$-value & 0.0000 & 0.0000 & 0.0000 \\
Observations & 6324 & 6324 & 6324 \\
\hline & DLTOPIX to DLDS & DLTOPIX to DLDN & DLTOPIX to DLNS \\
\hline Correlation coefficient & $-0.1080 * * *$ & $-0.0883 * * *$ & $0.0646 * * *$ \\
$t$-value & 8.6382 & 7.0473 & 5.1505 \\
$p$-value & 0.0000 & 0.0000 & 0.0000 \\
Observations & 6324 & 6324 & 6324 \\
\hline
\end{tabular}

Panel B. Results for the before Lehman shock period from September 1, 1987 to September 12, 2008

\begin{tabular}{llll}
\hline & DLTOPIX to DLDOW & DLTOPIX to DLSP & DLTOPIX to DLNASDAQ \\
\hline Correlation coefficient & $0.3547 * * *$ & $0.3743 * * *$ & $0.3223 * * *$ \\
$t$-value & 26.8741 & 28.5913 & 24.1183 \\
$p$-value & 0.0000 & 0.0000 & 0.0000 \\
Observations & 5020 & 5020 & 5020 \\
\hline & DLTOPIX to DLDS & DLTOPIX to DLDN & DLTOPIX to DLNS \\
\hline Correlation coefficient & $-0.0572 * * *$ & $-0.0714 * * *$ & $0.0650 * * *$ \\
$t$-value & 4.0599 & 5.0681 & 4.6178 \\
$p$-value & 0.0000 & 0.0000 & 0.0000 \\
Observations & 5020 & 5020 & 5020 \\
\hline
\end{tabular}

Panel C. Results for the after Lehman shock period from September 16, 2008 to March 24, 2014

\begin{tabular}{llll}
\hline & DLTOPIX to DLDOW & DLTOPIX to DLSP & DLTOPIX to DLNASDAQ \\
\hline Correlation coefficient & $0.4726 * * *$ & $0.4793 * * *$ & $0.4885^{* * *}$ \\
$t$-value & 19.3431 & 19.6964 & 20.1950 \\
$p$-value & 0.0000 & 0.0000 & 0.0000 \\
Observations & 1303 & 1303 & 1303 \\
\hline & DLTOPIX to DLDS & DLTOPIX to DLDN & DLTOPIX to DLNS \\
\hline Correlation coefficient & $-0.2847 * * *$ & $0.0890 * * *$ \\
$t$-value & 10.7137 & $-0.2125 * * *$ & 3.2213 \\
$p$-value & 0.0000 & 7.8446 & 0.0013 \\
Observations & 1303 & 0.0000 & 1303
\end{tabular}

Notes: DLTOPIX is the first log difference of the daily closing price of TOPIX; the variable is computed as the percentage $\log$ return by multiplying 100 . We note that we use the percentage log return for all return variables. Similarly, DLDOW is the percentage log return of the Dow Jones; DLSP means that of S\&P 500; DLNASDAQ is that of the NASDAQ. Further, DLDS denotes the percentage log difference of the DS ratio, which is computed as the closing price of the Dow Jones divided by that of S\&P 500. Similarly, DLDN is the percentage log difference of the DN ratio, which is computed as the closing price of the Dow Jones divided by that of the NASDAQ; DLNS denotes the percentage log difference of the NS ratio, which is computed as the closing price of the NASDAQ divided by that of S\&P 500. *** denotes the statistical significance at the $1 \%$ level. 
Table 3. Tests of the average values of the time-varying correlation coefficients between the changes of the Nikkei 225 and the US variable changes

Panel A. Results for the full sample period from September 1, 1987 to March 24, 2014

\begin{tabular}{llll}
\hline & DLNIKKEI to DLDOW & DLNIKKEI to DLSP & DLNIKKEI to DLNASDAQ \\
\hline Correlation coefficient & $0.3845^{* * *}$ & $0.4036^{* * *}$ & $0.3664 * * *$ \\
$t$-value & 33.1156 & 35.0711 & 31.3107 \\
$p$-value & 0.0000 & 0.0000 & 0.0000 \\
Observations & 6324 & 6324 & 6324 \\
\hline & DLNIKKEI to DLDS & DLNIKKEI to DLDN & DLNIKKEI to DLNS \\
\hline Correlation coefficient & $-0.1135^{* * *}$ & $-0.0952 * * *$ & $0.0709 * * *$ \\
$t$-value & 9.0823 & 7.6043 & 5.6506 \\
$p$-value & 0.0000 & 0.0000 & 0.0000 \\
Observations & 6324 & 6324 & 6324 \\
\hline
\end{tabular}

Panel B. Results for the before Lehman shock period from September 1, 1987 to September 12, 2008

\begin{tabular}{llll}
\hline & DLNIKKEI to DLDOW & DLNIKKEI to DLSP & DLNIKKEI to DLNASDAQ \\
\hline Correlation coefficient & $0.3353 * * *$ & $0.3559 * * *$ & $0.3132 * * *$ \\
$t$-value & 25.2087 & 26.9810 & 23.3620 \\
$p$-value & 0.0000 & 0.0000 & 0.0000 \\
Observations & 5020 & 5020 & 5020 \\
\hline & DLNIKKEI to DLDS & DLNIKKEI to DLDN & DLNIKKEI to DLNS \\
\hline Correlation coefficient & $-0.0616 * * *$ & $-0.0794 * * *$ & $0.0731^{* * *}$ \\
$t$-value & 4.3700 & 5.6418 & 5.1951 \\
$p$-value & 0.0000 & 0.0000 & 0.0000 \\
Observations & 5020 & 5020 & 5020
\end{tabular}

Panel C. Results for the after Lehman shock period from September 16, 2008 to March 24, 2014

\begin{tabular}{llll}
\hline & DLNIKKEI to DLDOW & DLNIKKEI to DLSP & DLNIKKEI to DLNASDAQ \\
\hline Correlation coefficient & $0.5054^{* * *}$ & $0.5107^{* * *}$ & $0.5181^{* * *}$ \\
$t$-value & 21.1252 & 21.4278 & 21.8501 \\
$p$-value & 0.0000 & 0.0000 & 0.0000 \\
Observations & 1303 & 1303 & 1303 \\
\hline & DLNIKKEI to DLDS & DLNIKKEI to DLDN & DLNIKKEI to DLNS \\
\hline Correlation coefficient & $-0.2951^{* * *}$ & $-0.2151^{* * *}$ & $0.0852^{* * *}$ \\
$t$-value & 11.1393 & 7.9444 & 3.0845 \\
$p$-value & 0.0000 & 0.0000 & 0.0021 \\
Observations & 1303 & 1303 & 1303 \\
\hline
\end{tabular}

Notes: DLNIKKEI is the first log difference of the daily closing price of the Nikkei 225; the variable is computed as the percentage $\log$ return by multiplying 100 . We note that we use the percentage log return for all return variables. Similarly, DLDOW is the percentage log return of the Dow Jones; DLSP means that of S\&P 500; DLNASDAQ is that of the NASDAQ. Further, DLDS denotes the percentage log difference of the DS ratio, which is computed as the closing price of the Dow Jones divided by that of S\&P 500. Similarly, DLDN is the percentage log difference of the DN ratio, which is computed as the closing price of the Dow Jones divided by that of the NASDAQ; DLNS denotes the percentage log difference of the NS ratio, which is computed as the closing price of the NASDAQ divided by that of S\&P 500. *** denotes the statistical significance at the $1 \%$ level. 


\section{Conclusions}

This paper empirically explored which US stock price index is strongly influenced by the dynamics of the Japanese stock markets by analyzing the US stock price index ratios. Our empirical tests revealed the following interesting evidence. First, (1) we clarified that all US stock returns of the Dow Jones, S\&P 500, and NASDAQ Composite indices were statistically significantly positively influenced by the returns of TOPIX and the Nikkei 225. Moreover, we also found that (2) very interestingly, the changes of the NASDAQ-S\&P ratio were statistically significantly positively influenced by the returns of TOPIX and the Nikkei 225; on the other hand, the changes of the Dow-S\&P ratio and Dow-NASDAQ ratio were statistically significantly negatively influenced by the returns of TOPIX and the Nikkei 225 . These relations between the returns of TOPIX and the Nikkei 225 and the US stock price index ratios were always clearly shown in all three sample periods employed in this paper. Therefore, our results suggest that (3) the NASDAQ index was most strongly positively connected with the Japanese stock market dynamics. In more detail, in our analyzing sample periods, NASDAQ index was more strongly influenced by the Japanese stock markets than S\&P 500, and S\&P 500 was more strongly associated with the Japanese stock markets than Dow Jones.

Furthermore, we consider that we can emphasize the importance and usefulness of the research as to stock price index ratios as follows. (1) First, as our Figure 1 demonstrates, we can recognize the market valuation differentials of some different industries by watching the dynamics of stock price index ratios because the industrial construction of each stock price index is not the same. For example, the IT bubbles in the US can be clearly recognized in our graph of the NS ratio in Panel C of Figure 1. (2) Second, as our third derived evidence described above demonstrates, by analyzing the relations among the time-series changes of stock price index ratios, we can derive more detailed information on the dynamics of the stock markets. Numerous stock price indices are recently being developed in many international equity markets; however, the differentials of these different indices would not be so strongly paid attention to nor correctly understood in general. Thus we consider that it is much important for us to grasp the differentials of these indices exactly by carefully examining the linkage among the dynamics of stock price index ratios constructed by them.

Hence as we emphasized, further empirical examinations with regard to other international stock price index ratios are highly important in order to deepen and accumulate our knowledge of the actual international stock market dynamics and linkage. Thus further analyses of international stock price index ratios from various viewpoints shall be one of my future tasks.

\section{Acknowledgements}

I am particularly grateful to the kind repeated invitation from the journal to write to this journal. In addition, I greatly thank the Editor and anonymous reviewers for their kind comments to this paper. I also appreciate the Japan society for the promotion of science and the Chuo university grant for special research for their generous financial assistance to this research.

\section{References}

Anderson, K., Brooks, C., \& Katsaris, A. (2010). Speculative bubbles in the S\&P 500: Was the tech bubble confined to the tech sector? Journal of Empirical Finance, 17, 345-361. http://dx.doi.org/10.1016/j.jempfin.2009.12.004

Becker, R., Clements, A. E., \& McClelland, A. (2009). The jump component of S\&P 500 volatility and the VIX index. Journal of Banking \& Finance, 33, 1033-1038. http://dx.doi.org/10.1016/j.jbankfin.2008.10.015

Brock, W., Lakonishok, J., \& LeBaron, B. (1992). Simple technical trading rules and the stochastic properties of stock returns. Journal of Finance, 47, 1731-1764. http://dx.doi.org/10.1111/j.1540-6261.1992.tb04681.x

Chen, H. L., \& De Bondt, W. (2004). Style momentum within the S\&P-500 index. Journal of Empirical Finance, 11, 483-507. http://dx.doi.org/10.1016/j.jempfin.2004.04.005

Choudhry, T. (2010). World War II events and the Dow Jones industrial index. Journal of Banking \& Finance, 34, 1022-1031. http://dx.doi.org/10.1016/j.jbankfin.2009.11.004

Darrat, A. F., Rahman, S., \& Zhong, M. (2003). Intraday trading volume and return volatility of the DJIA stocks: A note. Journal of Banking \& Finance, 27, 2035-2043. http://dx.doi.org/10.1016/S0378-4266(02)00321-7

Day, T. E., \& Wang, P. (2002). Dividends, nonsynchronous prices, and the returns from trading the Dow Jones Industrial Average. Journal of Empirical Finance, 9, 431-454. http://dx.doi.org/10.1016/S0927-5398(02)00004-X

Durham, G. B. (2007). SV mixture models with application to S\&P 500 index returns. Journal of Financial Economics, 85, 822-856. http://dx.doi.org/10.1016/j.jfineco.2006.06.005

Engle, R. F., \& Kroner, K. F. (1995). Multivariate Simultaneous Generalized Arch. Econometric Theory, 11, 122-150. http://dx.doi.org/10.1017/S0266466600009063

Gospodinov, N., \& Jamali, I. (2012). The effects of Federal funds rate surprises on S\&P 500 volatility and volatility risk 
premium. Journal of Empirical Finance, 19, 497-510. http://dx.doi.org/10.1016/j.jempfin.2012.04.009

Kaeck, A., \& Alexander, C. (2012). Volatility dynamics for the S\&P 500: Further evidence from non-affine, multi-factor jump diffusions. Journal of Banking \& Finance, 36, 3110-3121. http://dx.doi.org/10.1016/j.jbankfin.2012.07.012

Karolyi, G. A., \& Stulz, R. M. (1996). Why do markets move together? An investigation of US-Japan stock return comovements. Journal of Finance, 51, 951-986. http://dx.doi.org/ 10.1111/j.1540-6261.1996.tb02713.x

Mollick, A. V., \& Assefa, T. A. (2013). U.S. stock returns and oil prices: The tale from daily data and the 2008-2009 financial crisis. Energy Economics, 36, 1-18. http://dx.doi.org/10.1016/j.eneco.2012.11.021

Narayan, P. K., \& Thuraisamy, K. S. (2013). Common trends and common cycles in stock markets. Economic Modelling, 35, 472-476. http://dx.doi.org/10.1016/j.econmod.2013.08.002

\section{$(\mathrm{cc})$ EY}

This work is licensed under a Creative Commons Attribution 3.0 License. 